\title{
Design of active inductor-based butterworth and chebyshev microwave bandpass filters in standard 0.18 $\mu \mathrm{m}-\mathrm{CMOS}$ technology
}

\author{
Jarjar Mariem, Pr. EL Ouazzani Nabih \\ Laboratoire Signaux, Systemes et Composants (LSSC), Faculté des Sciences et Techniques de Fes (FSTF) \\ Universite Sidi Mohamed Ben Abdellah (USMBA), Route Immouzzer, B.P. 2202, Fes-MaroC, Marocco
}

\begin{tabular}{|c|c|}
\hline Article Info & ABSTRACT \\
\hline Article history: & In this paper we propose a synthesis of microwave active filters having \\
\hline & Butterworth and Chebyshev responses in the frequency range $1 \mathrm{GHz}-2 \mathrm{GHz}$. \\
\hline Received Nov 10, 2018 & The filter fundamental block, used to build an active inductor, consists of \\
\hline Revised Jan 25, 2019 & CMOS-based Operational Transconductance Amplifier (OTA) circuits. \\
\hline Accepted Feb 7, 2019 & $\begin{array}{l}\text { These amplifiers are made out of simple current mirror using MOS } \\
\text { transistors. The simulation procedure has been carried out through PSPICE }\end{array}$ \\
\hline Keywords: & $\begin{array}{l}\text { software showing good performances regarding scattering parameters in } \\
\text { terms insertion losses, of out-of-band rejection and phase. }\end{array}$ \\
\hline
\end{tabular}

$0.18 \mu \mathrm{m}$ CMOS

Active inductor

Current mirror

Microwave filter

OTA

Copyright $₫ 2019$ Institute of Advanced Engineering and Science. All rights reserved.

\section{Corresponding Author:}

Jarjar Mariem,

Laboratoire Signaux, Systemes et Composants (LSSC),

Faculté des Sciences et Techniques de Fés (FSTF).

Universite Sidi Mohamed Ben Abdellah (USMBA), Route Immouzzer, B.P. 2202, Fés-Maroc,Morocco

Email: mariem.jarjar@usmba.ac.ma

\section{INTRODUCTION}

Nowadays, microwave active circuits are widely used in wireless communication systems. Much effort has been made to fulfil a great demand for smaller and cheaper devices. Active filters are amongst important parts to be considered since they facilitate frequency tuning and can be implemented in standard Integrated Circuit (IC) technology.There are several active filter configurations, the most common are switched capacitor filters [1]-[2], Q-enhanced LC filters [3], coupled LC resonators and gyrator-C or active inductor filters [4-6].

Microwave active filters based on integrated inductors rather than off-chip component reduce not only the cost of manufacturing, but also the power consumption [7]. The filtering technique is based on a circuit topology that enables to invert impedance. The objective is that from a capacitor used in gyrator coupling we emulate a high quality factor inductor.

CMOS technology has many applications in high frequency bandpass filter domain [8]-[9]. There are several interesting characteristics. This tendency has become more successful as CMOS integrated filters present good performances such as high center frequency, low insertion loss and less power consumption.Unfortunately, this technique leads to some important constraints related to standard CMOS properties that result in limitation to increase the quality factor and small frequency tuning range [10].

In order to obtain better responses, several improvements have been carried out. For instance, [11] proposed an active inductor with a cascode structure to enhance the quality factor. A tunable inductor with a feedback parallel resonance circuit inserted into the structure is also described in [12]. 
In many other cases, active inductors can be realized by means of Operational Transconductance Amplifier (OTA) circuits [13]-[14]. The basic configuration of the gyrator consists of two OTA circuits, connected in a negative feedback and loaded with capacitor [14]. Throughout this work we have been interested in the use of $0.18 \mu \mathrm{m}$ CMOS-based components as key elements yielding numerous advantages such as high resistance to noise and good linearity. As we seek a reduced number of transistors, the building blocks of the OTA are made particularly from simple current mirror circuits using NMOS differential pairs [15].

The high quality performances of the newly proposed OTA rely on the reduced number of transistors and also the possibility of operating in the microwave domain. For this purpose, we propose a design procedure of microwave bandpass active filters as an application of the OTA-based inductors. Indeed, second and third order filters according to Butterworth and Chebyshev responses are dealt with. C-coupled structure allows us to overcome the constraint of active inductor losses thanks to the incorporation of the admittance J-inverters into the circuit [16].

This paper is organized as follows. Section II deals with the design of a grounded active inductor using CMOS-based OTA circuits that are made from simple current mirrors. A procedure of synthesizing C-coupled active microwave bandpass filters is developed in section III. This is achieved thanks to the low pass prototype to bandpass prototype transformation. In section IV, Butterworth and Chebyshev bandpass filters are designed. Simulation results are given and compared. Section V concludes the proposed work.

\section{GROUNDED ACTIVE INDUCTOR DESIGN}

\subsection{CMOS-based OTA}

As well known, an OTA is a voltage controlled current source that can be made from different types of transistors [17]. The most suitable component for the targeted performances is CMOS device thanks to its low power consumption and reduced size. Among the interesting and available basic blocks, we have chosen a simple current mirror circuit that consists of NMOS differential pair, connected with two PMOS transistors according to the common gate configuration [18]. Figure 1 shows the topology of the proposed OTA.

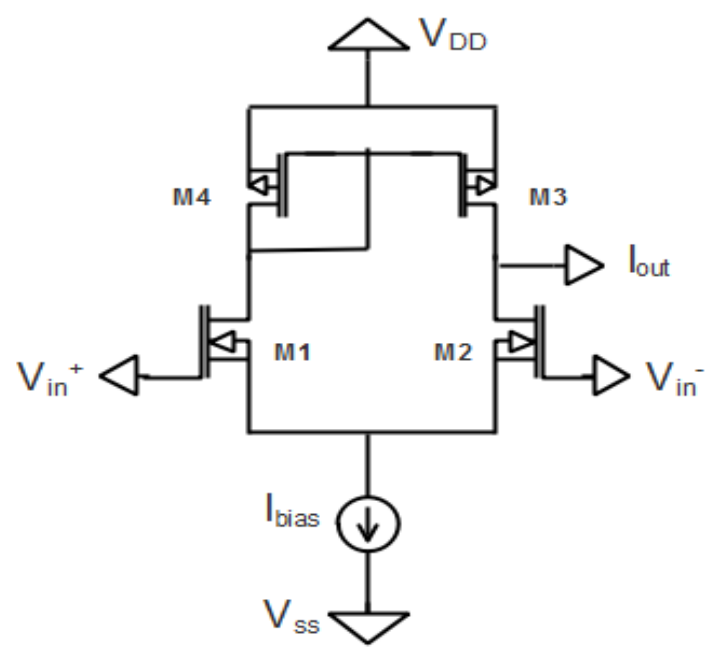

Figure 1. CMOS-based OTA circuit

(1) gives the MOS transistor transconductance $g_{m}$.

$$
g_{m}=\sqrt{2 k_{p} I_{b i a s} \frac{W}{L}}
$$

where $k_{\mathrm{p}}$ is the Boltzmann's constant, $\mathrm{W}$ is the width, $\mathrm{L}$ is the length of the transistor and $\mathrm{I}_{\text {bias }}$ represents the biasing current [19].

We point out that all the used transistors have the same size and should operate in the saturation region. As a result, the OTA's transconductance $\mathrm{G}_{\mathrm{m}}$ and $\mathrm{g}_{\mathrm{m}}$ are equal: $\mathrm{G}_{\mathrm{m}}=\mathrm{g}_{\mathrm{m}}$. 


\subsection{Proposed Active Inductor}

As mentioned in section I, we are strongly interested in the gyrator-C topology to realize a grounded active inductor. The proposed configuration includes two simple current mirror-based OTA circuits [20], connected back to back in a negative feedback as illustrated in Figure 2(a); The gate-source capacitance $\mathrm{C}_{\mathrm{gs}}$ of the transistor $\mathrm{M}_{7}$ stands for the grounded $\mathrm{C}$ as indicated in Figure 2(b). From (2) we can easily derive an equivalent RLC resonant network to the circuit under study as shows in Figure 3.

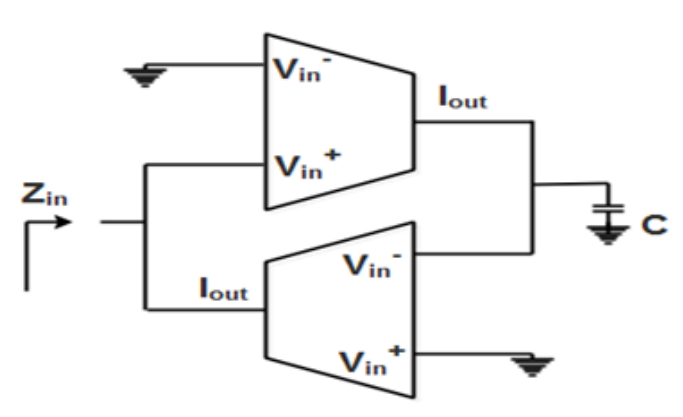

(a) Real structure of the proposed active inductor

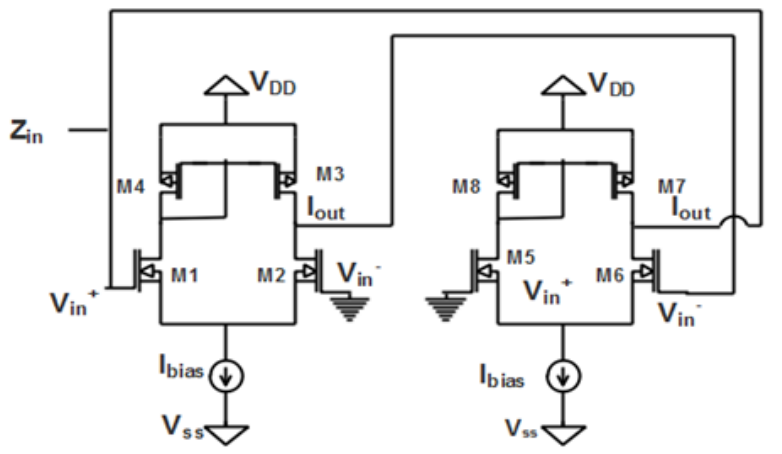

(b) Active inductor model

Figure 2. Active inductor structure

The small signal analysis of the circuit yields the input admittance expression $Y_{\text {in }}$ given by (2).

$$
Y_{i n}=\frac{I_{i n}}{V_{i n}}=G_{m}+\frac{G_{m}^{2}}{j \omega C_{g s}+G_{d s}}+j \omega C_{g s}
$$

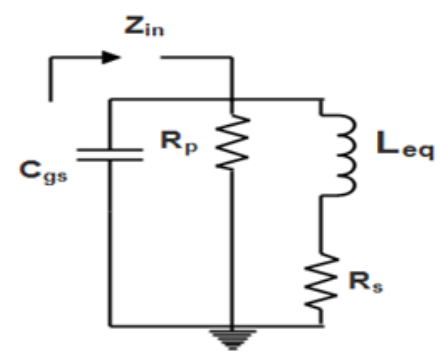

Figure 3. Equivalent RLC circuit

All the elements are described by the following relations.

$$
\begin{aligned}
& L_{e q}=\frac{C_{g s}}{G_{m}^{2}} \\
& R_{s}=\frac{G_{d s}}{G_{m}^{2}} \\
& R_{p}=\frac{1}{G_{m}} \\
& C_{p}=C_{g s}
\end{aligned}
$$


As a result, the resonance frequency and the quality factor are expressed according to (7) and (8), respectively.

$$
\begin{aligned}
& f_{0}=\frac{1}{2 \pi \sqrt{L_{e q} C_{g s}}} \\
& Q=\frac{I M G\left(1 / Y_{i n}\right)}{R E A L\left(1 / Y_{i n}\right)}
\end{aligned}
$$

The proposed active inductor has then been simulated by means of PSPICE software within the frequency range $1 \mathrm{GHz}-2 \mathrm{GHz}$. We have chosen the $0.18 \mu-\mathrm{CMOS}$ technology to integrated PMOS and NMOS transistors into the circuit with respect to the following parameters:

$$
\text { a. Width: } \mathrm{W}=4 \mu \mathrm{m} \text {. }
$$

b. Length: $\mathrm{L}=2 \mu \mathrm{m}$.

In addition, the biasing conditions are described by:

a. $\mathrm{I}_{\text {bias }}=260 \mu \mathrm{A}$

b. $\quad \mathrm{V}_{\mathrm{DD}}=-\mathrm{Vss}=1.8 \mathrm{~V}$

Figure 4 shows a very small variation of the inductance so that we can assume it a constant value. We also notice the quality factor reaches a value as high as 5000 confirming the predicted performances. The simulation results demonstrated important characteristics in terms of filtering-related properties.

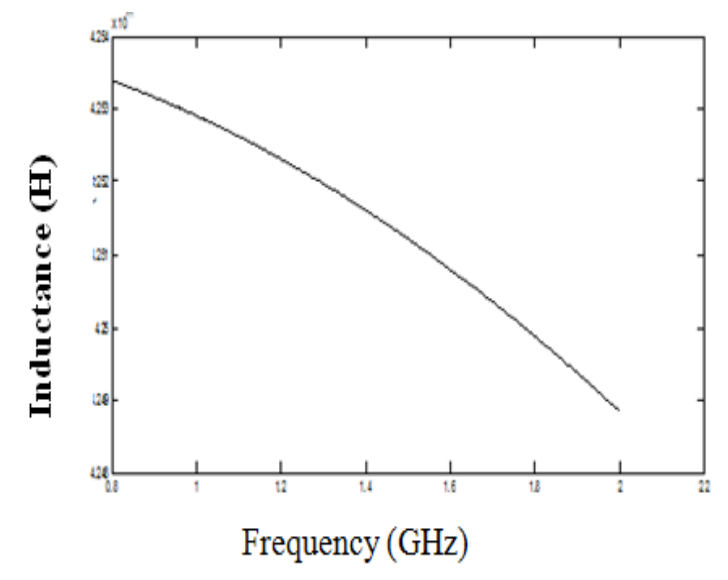

(a)

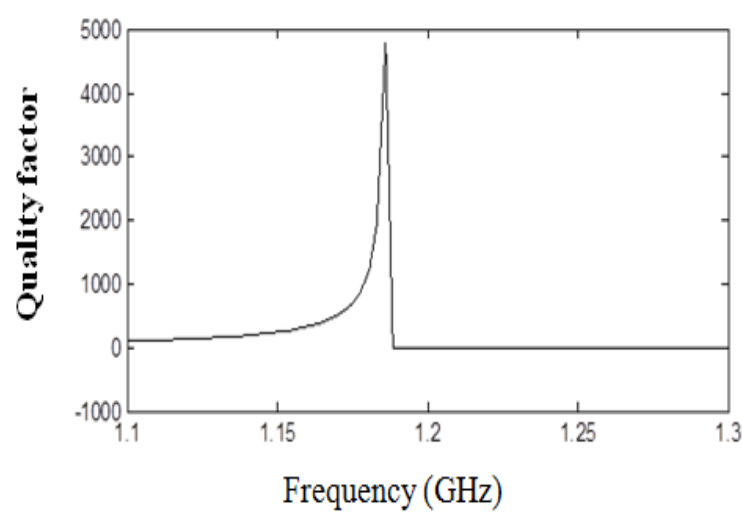

(b)

Figure 4. (a) Inductance value, (b) Quality factor

\section{C-COUPLED DESIGN PROCEDURE OF BANDPASS FILTERS}

\subsection{Impedance Inverter}

Lumped elements bandpass filters can be realized according to the ladder structure made from a series and parallel LC resonators.Knowing the fact that the insertion of too many inductors results in a great deal of losses, we propose to implement admittance-J inverters for better performances, as an alternative solution [21].

We remind that a perfect admittance inverter functions as a quarter-wave lossless transmission line of characteristic admittance $\mathrm{Y}_{\mathrm{c}=\mathrm{J}}$. They are reciprocal two port linear circuits that usually convert a ladder network, having series impedances as shunt admittances, to an equivalent topology with only parallel admittances. Thus, load admittance is converted into its inverse according to (9).

$$
Y_{i n}=\frac{J^{2}}{Y_{L}}
$$


Taking into account the design requirements, admittance inverters are inserted into the circuit between LC parallel resonators that are consequently transformed to series ones as illustrated in Figure 5. Figure 6 presents the structure of a capacitor-based pi-network used as the admittance inverter we have adopted for the synthesis.

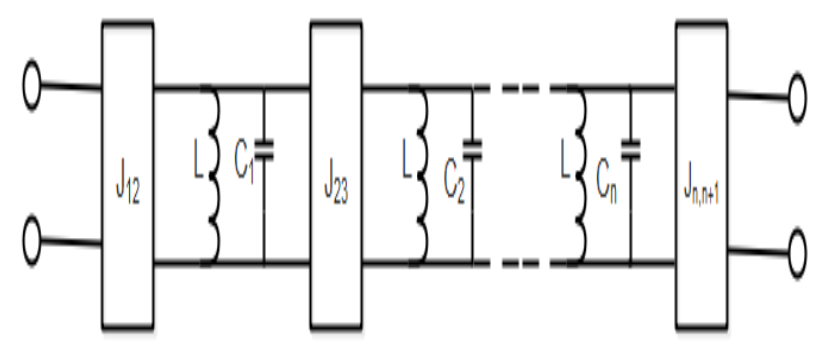

Figure 5 .Bandpass filter structure

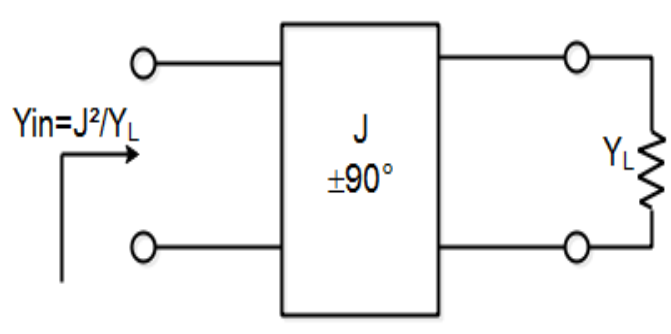

(a)

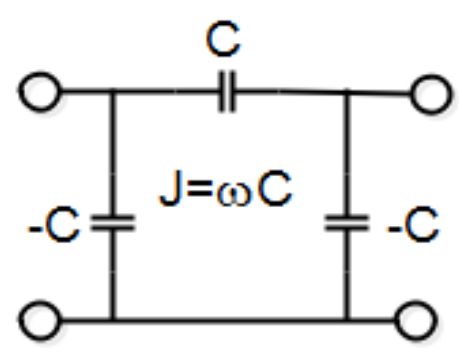

(b)

Figure 6. Admittance inverter, (b) pi network of capacitors

\subsection{Procedure of Calculating Capacitors}

On the basis of the C-coupled filters structure, presented in Figure 7, the proposed circuit is then built taking into account the implementation of the admittance inverters. Figure 7 shows the whole configuration.

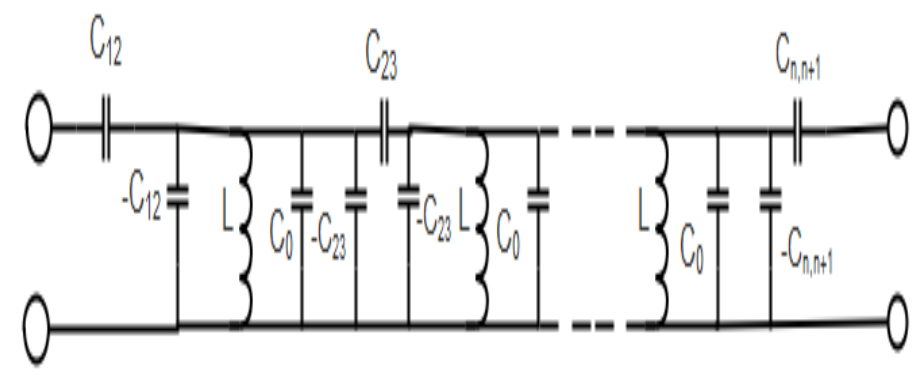

Figure 7. Filter implementation

We point out that $\mathrm{L}$ stands for an inductance, C-coupled and C'-resonator capacitors are evaluated according to (12) and (13), $\mathrm{n}$ is the order of the filter and $\mathrm{g}_{\mathrm{i}}$ are the normalized element values of the low pass prototype. In addition, the input and the output inverters of the filter are given by (17) and (18), respectively:

$$
C_{(n, n+1)}=\frac{J(n)}{2 \pi f_{0} \sqrt{\left(1-\left(J(n) \times Z_{0}\right)^{2}\right.}}
$$




$$
C_{(n)}^{\prime}=C_{0}-C_{(n, n+1)}-C_{(n+1, n+2)}
$$

where

$$
C_{0}=\frac{1}{\left(2 \pi f_{0}\right)^{2} L}
$$

for $1<\mathrm{i}<\mathrm{n}$

$$
J(i)=\frac{2 \pi f_{0} \times C_{0} \times \Delta}{\sqrt{g_{(i-1)} \times g_{(i)}}}
$$

$\Delta=\frac{B W}{f_{0}}$

$$
J(1)=\sqrt{\frac{2 \pi f_{0} \times C_{0} \times \Delta}{Z_{0} \times 1 \times g_{(1)}}}
$$

$$
J(n)=\sqrt{\frac{2 \pi f_{0} \times C_{0} \times \Delta}{Z_{0} \times g_{(n-1)} \times g_{(n)}}}
$$

where $\mathrm{Z}_{0}$ is the characteristic impedance. As a result, we obtain the simplified topology shown in Figure 8 .

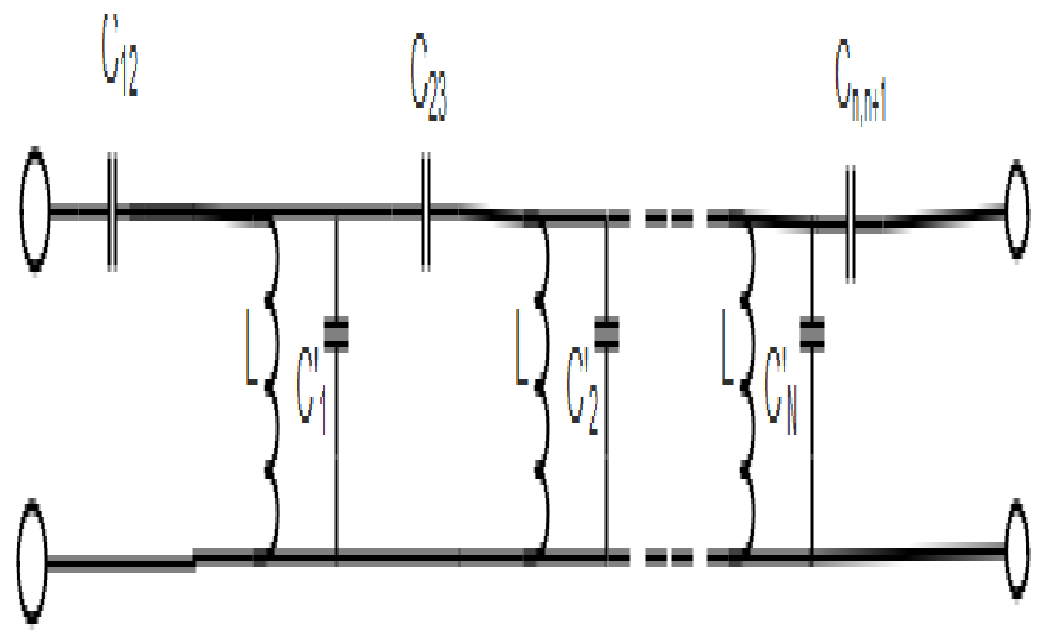

Figure 8. Final configuration

\section{SECOND ORDER ACTIVE BANDPASS FILTERS}

In this section, we focus on the design of second order bandpass filters according to the Butterworth and $1 \mathrm{~dB}$-ripple Chebyshev prototype within the frequency range $1 \mathrm{GHz}-2 \mathrm{GHz}$. Figure 9 presents the proposed second order bandpass filter and Table 1 shows the key parameters related to the desired filter performances. Values of different capacitors are indicated in Table 2.

The simulation process has been carried out by means of PSPICE software and led to the $S_{11}$ and $S_{21}$ responses, presented and compared in Figure 10 .We clearly notice that both filters have excellent performances in terms of low insertion losses and linear phase response in the bandwidth. As expected, the Chebyshev-type filter ensures a better out-of-band rejection. 


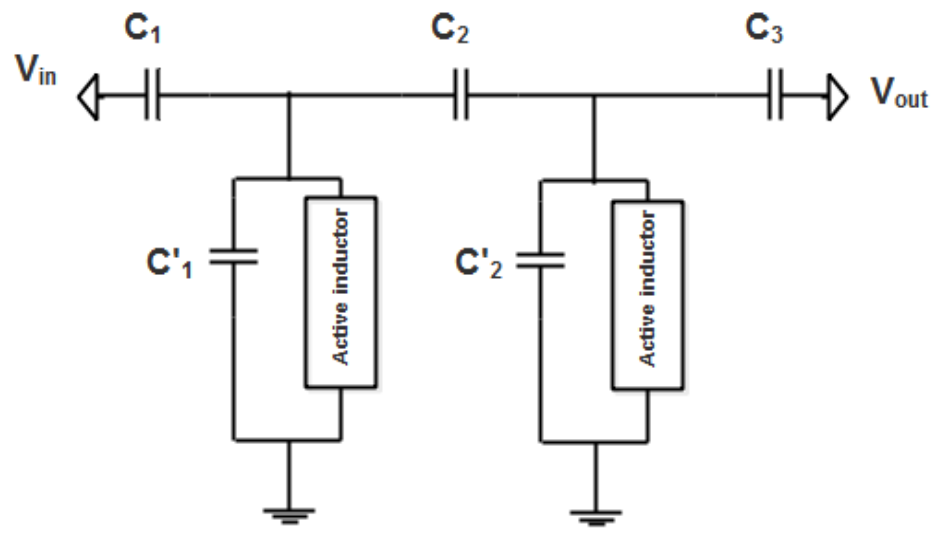

Figure 9. Second order bandpass filter

Table 1. Filters' Parameters

\begin{tabular}{cc}
\hline Parameter & Value \\
\hline Bandwidth BW & $7 \mathrm{MHz}$ \\
Center frequency f0 & $1.16 \mathrm{GHz}$ \\
Active inductance L & $42 \mathrm{pH}$ \\
\hline
\end{tabular}

Table 2. Bandpass Filters' Capacitors

\begin{tabular}{cccccc}
\hline & $\mathrm{C} 1(\mathrm{pF})$ & $\mathrm{C} 2(\mathrm{pF})$ & $\mathrm{C} 3(\mathrm{pF})$ & $\mathrm{C}^{\prime} 1(\mathrm{pF})$ & $\mathrm{C}^{\prime} 2(\mathrm{pF})$ \\
\hline Butterworth & 4.15 & 1.91 & 4.15 & 444.26 & 444.26 \\
1dB ripple Chebyshev & 2.97 & 2.41 & 2.97 & 443.65 & 443.65 \\
\hline
\end{tabular}

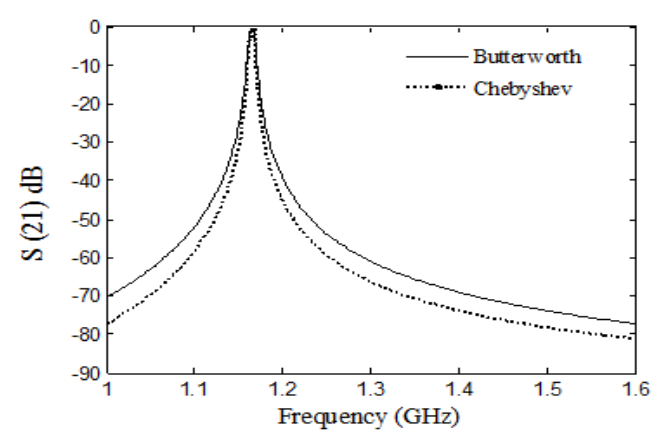

(a)

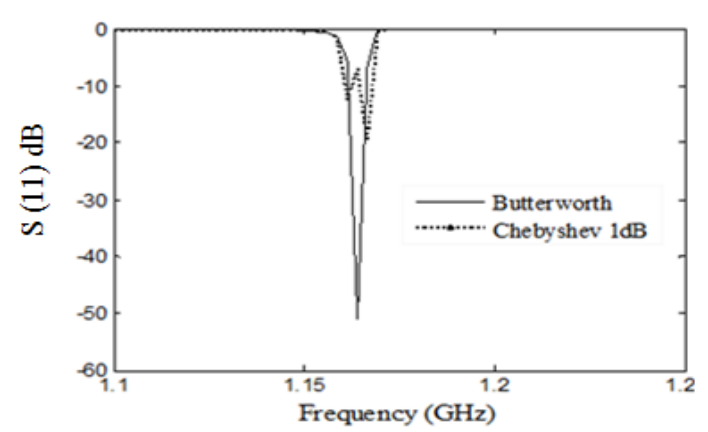

(b)

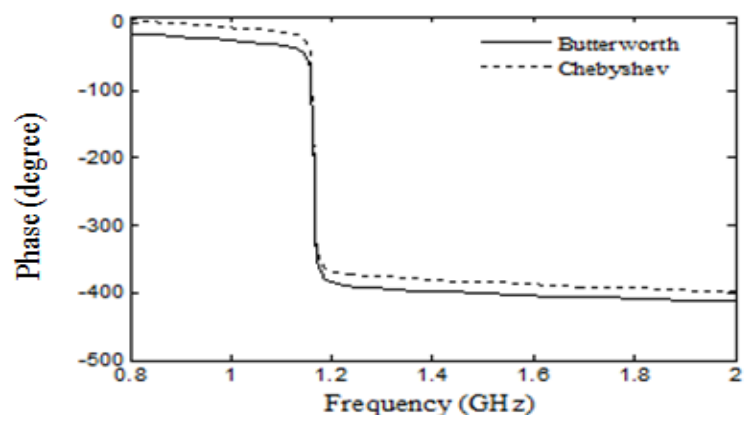

(c)

Figure 10. Filter responses (a) S21, (b) S11 and (c) phase 


\section{CONCLUSION}

A new $0.18 \mu \mathrm{m}-\mathrm{CMOS}$-based OTA circuit functioning at microwave frequencies with high quality performances has been proposed. To take advantage of circuit, C-coupled Butterworth and Chebyshev microwave bandpass filters have been synthesized using active inductors, made from the proposed OTA. The developed design emphasized on second order filter circuits on the basis of the low pass prototype to bandpass prototype transformation.

The simulation results, obtained by means of PSPICE software, show good performances regarding the filter responses S11 and S21 within the bandwidth. It has been of great interest to perform a second order filter design in frequency range $1 \mathrm{GHz}-2 \mathrm{GHz}$ resulting in low losses and linear phase response.

\section{REFERENCES}

[1] Richard Schreier, José Silva, Jesper Steensgaard, Gabor C, Design-Oriented Estimation of Thermal Noise in Switched-Capacitor Circuits, IEEE TRANSACTIONS ON CIRCUITS AND SYSTEMS-I: REGULAR PAPERS, VOL. 52, NO. 11, NOVEMBER 2005.

[2] Rod Burt, Joy Zhang, A Micropower Chopper-Stabilized Operational Amplifier Using a SC Notch Filter With Synchronous Integration Inside the Continuous-Time Signal Path, IEEE JOURNAL OF SOLID-STATE CIRCUITS, VOL. 41, NO. 12, DECEMBER 2006

[3] William B. Kuhn, Naveen K. Yanduru, Adam S. Wyszynski, Q-Enhanced LC Bandpass Filters for Integrated Wireless Applications, IEEE TRANSACTIONS ON MICROWAVE THEORY AND TECHNIQUES, VOL. 46, NO. 12, DECEMBER 1998

[4] Yue Wu, Xiaohui Ding, Mohammed Ismail, Håkan Olsson, RF Bandpass Filter Design Based on CMOS Active Inductors, IEEE TRANSACTIONS ON CIRCUITS AND SYSTEMS-II: ANALOG AND DIGITAL SIGNAL PROCESSING, VOL. 50, NO. 12, DECEMBER 2003

[5] David C'ordova, Jorge De la Cruz, Carlos Silva, A 2.3-GHz CMOS High-Q Bandpass Filter Design using an Active Inductor, XV Workshop Iberchip, Buenos Aires - Argentina, 25 - 27 de Marzo de 2009

[6] Manjula V. Katageri, M.M.Mutsaddi, LC Active Low Pass Ladder Filter by Lossless Floating Inductor Gyrator, IOSR Journal of Applied Physics (IOSR-JAP) e-ISSN: 2278-4861. Volume 3, Issue 3 (Mar. - Apr. 2013), PP 01-03

[7] W. El hamdani, M.El bekkali, M.ALAMI, F. Temcamani, B.Delacressonnière, CMOS RF Bandpass Filter Design using a Compensated Active Inductor, IOSR Journal of Electrical and Electronics Engineering (IOSR-JEEE) $e$ ISSN: 2278-1676,p-ISSN: 2320-3331, Volume 10, Issue 2 Ver. III (Mar-Apr. 2015), PP 53-58

[8] Yue Wu, Xiaohui Ding, Mohammed Ismail and $\mathrm{H}$ bOls son, CMOS Active Inductor and its Application in FW Bandpass Filter, 2004 IEEE Radiq Frequency Integrated Circuits Symposium

[9] Mahdi Ebrahimzadeh, Farzan Rezaei, Siavash Rezaei A New Active Inductor and Its Application to Wide Tuning Range LC Oscillator, International Journal of Soft Computing and Engineering (IJSCE) ISSN: 2231-2307, Volume1, Issue-5, November 2011

[10] B.K.Mishra, Sandhya Save, Amruta A.Ranade, Improved Quality-Factor of 0.18-um Active Inductor by a Current Reuse Design, International Journal of Computer Applications (0975-8887) International Conference and Workshop on Emerging Trends in Technology 2013

[11] Manjula , Dr.S.Malarvizhi, Performance Analysis of Active Inductor Based Tunable Band Pass Filter for Multiband RF Front end, International Journal of Engineering and Technology (IJET), Vol 5 No 3 Jun-Jul 2013

[12] Kyu Seok Hwang,Choon Sik Cho, Jae W. Lee, Jaeheung Kim High Quality-Factor and Inductance of Symmetric Differential-Pair Structure Active Inductor Using a Feedback Resistance Design 978-1-4244-1780-2008IEEE

[13] Rajeshwari S. Mathad, M. M. Mutsaddi, S. V. Halse, Design of OTA-C Active Low Pass Filter Using Multiple OTA's, IOSR Journal of Applied Physics (IOSRJAP) ISSN - 2278-4861 Volume 1, Issue 4 (July-Aug. 2012), PP 08-12

[14] Haiqiao Xiao, Rolf Schaumann, W. Robert Daasch, Phillip K. Wong and Branimir PejcinovicA RADIOFREQUENCY CMOS ACTIVE INDUCTOR AND ITS APPLICATION IN DESIGNING HIGH- $Q$ FILTERS, 10.1109/ISCAS.2004.1328974IEEE,2004

[15] Kalpesh B. Pandya, Kehul A. shah, Performance Evaluation of Different Types of CMOS Operational Transconductance Amplifier International Journal of Science and Research (IJSR), India Online ISSN: 2319-7064

[16] Biljana P. Stošić, Nebojša S. Dončov, Synthesis and Use of Wave Digital Networks of Admittance Inverters , December, 2013 Microwave Review

[17] Randall L. Geiger and Edgar Sánchez-Sinencio Active Filter Design Using Operational Transconductance Amplifiers: A Tutorial, IEEE Circuits and Devices Magazine, Vol. 1, pp.20-32, March 1985.

[18] Vivek Pant, Shweta Khurana, Optimal High Performance Self Cascode CMOS Current Mirror, Global Journal of Computer Science and Technology Volume 11 Issue 15 Version 1.0 Septem-ber 2011

[19] R. Jacob Baker CMOS Circuit Design, Layout, and Simulation Third Edition IEEE Press Series on Microelectronic Systems

[20] JARJAR Mariem,EL OUAZZANI Nabih Synthesis of a microwave CMOS active inductor using simple current mirror-based operational Transconductance Amplifier (OTA) International Journal of Scientific \& Engineering Research, Volume 7, Issue 8, August-2016 ISSN 2229-5518

[21] Zoheir SASSI Docteur de l’Université de Limoges Électronique des Hautes Fréquences et Optoélectronique 2006 Filter design by the insertion loss method 389 


\section{BIOGRAPHIES OF AUTHORS}

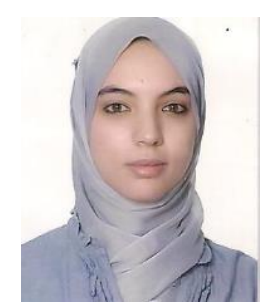

Mariem Jarjar She received the master degree in industrial engineering from the Faculty of science and techniques of Fès, Morocco in 2014. She is currently working towards the Ph.D degree at the same Faculty, with her research focus on EMC problems and developing techniques to reduce insertion losses of RF filters

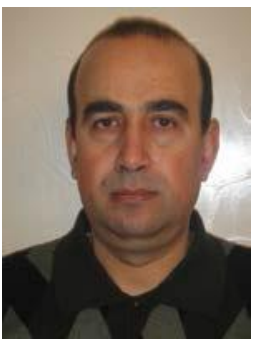

Nabih El Ouazzani was born in Safi, Morocco in 1964. He received the Ph.D degree in microwave circuits, especially microwave filters, from the University of Limoges - France at the Xlim Institute in 1995. He has been carrying out many activities with respect to research and education. The disciplines that are relevant to his expertise are high frequency technology and telecommunication technology. He is also involved in the research area of electromagnetic compatibility (EMC) in VLSI and MMIC circuits. The methods of simulation and analysis are based upon modeling and applying the numerical code FDTD. He has authored and co-authored numerous publications in the fields of recursive microwave filters, planar circuit interconnections, skin effect and arbitrary non uniform transmission lines. Prof. El Ouazzani has been, since 1995, a professor at the faculty of science and techniques-Fès, Morocco (FST-Fès). He co-organized many international conferences related the ICT and telecommunication subjects in Morocco and participated in scientific committees. He was at the head of the EMC unit within the LSSC laboratory (Laboratory of signals, systems and components) at the FSTFès (Morocco). 